\title{
Prediction Score for persisting perfusion defects after pulmonary embolism
}

\author{
Jan Mrozeka, Tereza Necasovab ${ }^{b}$ Michal Svobodab, Iveta Simkovac, Pavel Jansa ${ }^{d}$
}

\begin{abstract}
Aims. Long-term persistence of perfusion defect after pulmonaryembolism (PE) may lead to the development of chronic thromboembolic pulmonary hypertension. Identification of patients at risk of such a complication using a scoring system would be beneficial in clinical practice. Here, we aimed to derive a score for predicting persistence of perfusion defects after PE.

Methods. 83 patients after PE were re-examined 6, 12 and 24 months after the PE episode. Data collected at the time of PE and perfusion status during follow-ups were used for modelling perfusion defects persistence using the Cox proportional hazards model and validated using bootstrap method.

Results. A simple scoring system utilizing two variables (hemoglobin levels and age at the time of PE) was developed. Patients with hemoglobin levels over $140 \mathrm{~g} / \mathrm{L}$ who were older than 65 years were at the highest risk of perfusion defects; in patients with the same hemoglobin levels and age $<65$ years, the risk was reduced by $79 \%$, and by $89 \%$ in patients with hemoglobin $<140 \mathrm{~g} / \mathrm{L}$.

Conclusion. The proposed scoring system may be useful in clinical practice for identifying patients with high risk of persisting perfusion defects, flagging them for closer follow up, thus improving the effectiveness of long-term treatment of patients after PE.
\end{abstract}

Key words: pulmonary embolism, prediction score, perfusion defects, reperfusion, risk score, classification

Received: May 26, 2019; Accepted: July 2, 2019; Revised: June 4, 2019; Available online: September 13, 2019

https://doi.org/10.5507/bp.2019.033

(c) 2020 The Authors; https://creativecommons.org/licenses/by/4.0/

${ }^{a}$ Department of Cardiovascular Diseases, University Hospital Ostrava, 17. listopadu 1790, 70852 Ostrava-Poruba, Czech Republic bInstitute of Biostatistics and Analyses, Faculty of Medicine, Masaryk University Brno, Postovska 68/3, 602 00 Brno, Czech Republic 'National Institute of Cardiovascular Diseases and Slovak Medical University, Pod Krasnou horkou 7185/1, 83101 Bratislava - Nove Mesto, Slovak Republic

${ }^{d}$ Clinical Department of Cardiology and Angiology, 1st Faculty of Medicine, 2nd Medical Department, Charles University, U Nemocnice 499/2, 12808 Praha 2 - Nove Mesto, Czech Republic

Corresponding author: Jan Mrozek, e-mail:honzamrozek@email.cz

\section{INTRODUCTION}

Pulmonary embolism (PE) is one of the most common cardiovascular diseases ${ }^{1}$. Patients who survive the first days and the initial obstructive shock have a relatively good prognosis. The mortality rate of the PE between the seventh day and third month is approximately $5 \%$, the same as between the third and twelfth month, with most patients dying from consequences of the primary disease that actually caused the hypercoagulative state and subsequent PE (ref. ${ }^{2,3}$ ). Recurrence of pulmonary embolism is relatively rare - approx. $3 \%$ in the first 6 months and then approximately $3 \%$ per year ${ }^{4}$.

Nevertheless, patients who survive a PE episode may suffer from various functional or pathophysiological consequences, so-called PE-syndrome. This includes impaired thromboembolic resolution, persisting dysfunction and dilatation of the right ventricle, or reduced functional capacity and overall quality of life ${ }^{5}$. The most serious chronic complication of $\mathrm{PE}$ is the chronic thromboembolic pulmonary hypertension (CTEPH). It occurs in $1-5 \%$ of patients after a PE episode ${ }^{6-10}$. The pathogenesis of CTEPH is not yet fully understood. One of the theories explains the CTEPH development through an abnormal hemodynamic response to the obstruction of a part of the pulmonary vascular bed in some patients when the bronchopulmonary collateral vessels are dilated, which subsequently leads to damage of the microvasculature due to a high pressure in systemic bronchial arteries ${ }^{11}$. Disorders of resolution of thromboemboli and persisting perfusion defects that are not yet meeting criteria for classification as pulmonary hypertension are called a chronic thromboembolic disease (CTED) ( ref. $^{12}$ ).

The CTEPH diagnosis is unfortunately often delayed due to a slow development and non-specific symptoms of the disease. Such a delay in diagnosis can worsen the outcome of the patients ${ }^{13,14}$. A possible solution for reduction of the diagnostic delay could be close follow-ups of all patients after PE and their screening for CTEPH signs. However, neither the method of screening nor the time schedule for it has not been standardized and objections were raised against all diagnostic methods proposed as standard screening methods. Echocardiography can be inaccurate, especially at the early stages, burdened with a high number of both falsely negative and falsely positive results and a low cost-effectiveness ${ }^{15}$; pulmonary perfusion scintigraphy or CT angiography (CTA) are costly as well and, in addition, are associated with radiation burden ${ }^{16-18}$. 
Therefore, referring only patients with a high risk of developing CTEPH for such examinations appears to be a rational course of action.

One possible approach to the identification of patients with high risk of CTEPH development could lie in the use of a risk prediction score utilizing parameters detected at the time of the PE episode that would classify the level of risk of CTEPH development, thus providing a rule in/ rule out score.

The disorders of reperfusion do not only represent the initial factor in developing CTEPH; in addition, patients with residual thrombi are at increased risk of other chronic consequences of PE such as persisting dyspnea, reduced quality of life or right heart dysfunction and they should also be subject to close follow-up after a PE episode.

The aim of our work was therefore to formulate a prediction risk score for persisting reperfusion defects based on prospective observation of reperfusion in patients after the first PE episode.

\section{METHODS}

This study builds on results of a previously published analysis of long-term observation of reperfusion after the first episode of acute PE in patients diagnosed in four secondary hospitals in the Czech Republic and aims at creating a scoring system for prediction of the risk of persistence of perfusion defects.

Prior to inclusion in the study, all patients were informed about the study and signed an informed consent. The study protocol was approved by the local ethical committee.

Diagnosis, PE risk stratification, hospital care and subsequent follow-up on outpatient basis were performed according to current guidelines ${ }^{19}$. PE diagnosis was confirmed by pulmonary CTA or perfusion scintigraphy. All patients have undergone complete routine baseline inhospital work-up according to contemporary standards including assessment of medical history, concomitant diseases, complete laboratory tests, echocardiography, and/or other noninvasive methods.

Subsequently, patients were re-examined at month 6, 12 and 24 after the PE episode. Follow-up visits included clinical assessment, medical history, laboratory tests and echocardiography. Lung perfusion scintigraphy was performed only in patients with abnormal perfusion on previous assessment.

The data were used for modelling of perfusion defects persistence using the Cox proportional hazards model. The time from diagnosis of pulmonary embolism until the reperfusion, which was considered as an event in the survival analysis, was monitored. In four patients who experienced recurrent perfusion defects, only the period to the first reperfusion before the recurrence was used for modelling. In all patients who died over the course of the study, a complete reperfusion was recorded prior to their deaths; for this reason, death was not considered a competitive risk in the model.
The estimates of the regression coefficients of the final Cox model were validated using a bootstrap method for censored data with 1000 iterations. The proportional hazard assumption was assessed in individual iterations using the test of scaled Schoenfeld residuals. The 95 percentile range of bootstrap resulting estimates was used to estimate the confidence intervals of bootstrap-derived statistics. Persistence of perfusion defects according to the risk groups was analyzed using survival analysis, curves were estimated by the Kaplan-Meier method and the difference between groups was compared using the log-rank test. All calculations were performed in the R software ${ }^{20}$ with "survival" 21 and "boot"22 packages.

\section{RESULTS}

\section{Patients}

83 patients were included in the study $(56.6 \%$ were females, mean age 60 years). In total, 25 (30.1\%) patients suffered from provoked pulmonary embolism. The PE was classified as low risk in $35(42.2 \%)$, intermediate risk in $40(48.2 \%)$ and high risk in $8(9.6 \%)$ patients. Systemic thrombolysis was administered in 13 patients $(15.7 \%)$.

79 patients presented for re-examination 6 months after the initial event, 78 after 12 months and 74 after 24 months. Three patients died over the course of the study and 7 patients (8.4\%) experienced a recurrence of a thromboembolic event. In the 6th month after the initial episode of PE, the anticoagulant treatment was administered in 76 out of 79 patients $(96.2 \%) ; 57$ of that received warfarin, 5 rivaroxaban, 2 low molecular weight heparin and 14 were enrolled in the Hokusai trial (edoxaban/ warfarin). In the 12 th month, the anticoagulants were administered in 55 out of 77 patients $(71.4 \%)$ and in the 24 th month in 24 out of 75 (36.0\%). Over the study period, a complete reperfusion was achieved in 69 (83.1\%) patients; in three patients (3.5\%), CTEPH was detected after 24 months. The characteristics of the patient group are summarized in Table 1.

\section{Scoring system}

The survival of perfusion defects was initially modelled according to individual baseline parameters using univariate Cox regression models (Table 2).

Only the variables "hemoglobin" and "age", which was only significant in combination with hemoglobin, were included in the final scoring system. Of the other variables, none were significant either individually or in interaction with hemoglobin; some were not sufficiently represented for the purposes of modelling.

To simplify the applicability of the scoring system in clinical practice, both variables (hemoglobin and age) were categorized into two classes. This binary categorization was based on the threshold evaluated using receiver operating characteristic (ROC) analysis rounded down to the nearest meaningful value. Where hemoglobin was concerned, the cut-off was determined to be $140 \mathrm{~g} / \mathrm{L}$ (ROC: $141.5 \mathrm{~g} / \mathrm{L}, \mathrm{AUC}=0.792,95 \%$ IS: 0.679-0.906). Among 
Table 1. Patient characteristics at baseline.

\begin{tabular}{|c|c|c|c|c|}
\hline Parameter & & Reference range & Valid n & Characteristics \\
\hline \multicolumn{5}{|l|}{ pulmonaryembolism } \\
\hline Age (years) & & & 83 & $60.0(27.0 ; 78.0)$ \\
\hline Females & & & & $47(56.6 \%)$ \\
\hline BMI & & & 80 & $29.7(21.7 ; 38.8)$ \\
\hline FH VTE & & & & $18(21.7 \%)$ \\
\hline History of DVT & & & & $9(10.8 \%)$ \\
\hline \multirow{3}{*}{ PE risk stratification } & High & & & $8(9.6 \%)$ \\
\hline & Intermediate & & & $42(50.6 \%)$ \\
\hline & Low & & & $35(42.2 \%)$ \\
\hline Provoked PE & & & & $25(31.3 \%)$ \\
\hline \multicolumn{5}{|l|}{ Lab tests } \\
\hline CRP $(\mathrm{g} / \mathrm{L})$ & & $0-5$ & 80 & $24.5(6.0 ; 118.0)$ \\
\hline Troponin $(\mu \mathrm{g} / \mathrm{L})$ & & $0.00-0.03$ & 77 & $0.1(0.0 ; 2.3)$ \\
\hline $\mathrm{Hb}(\mathrm{g} / \mathrm{L})$ & & $120-160$ & 83 & $139.0(119.0 ; 160.0)$ \\
\hline Thrombocytes $\left(10^{9} / \mathrm{mL}\right)$ & & $150-400$ & 83 & $209.0(126.0 ; 352.0)$ \\
\hline D-dimers $(\mathrm{mg} / “ \mathrm{~L})$ & & $\leq 500$ & 73 & $2050.0(4.1 ; 8840.0)$ \\
\hline INR & & $1.8-1.2$ & 73 & $1.1(1.0 ; 1.3)$ \\
\hline APTT (s) & & 26.3-39.4 & 61 & $26.0(0.9 ; 44.0)$ \\
\hline \multicolumn{5}{|l|}{ Echo initial } \\
\hline LVIDd (mm) & & $<52$ & 82 & $44.0(33.0 ; 55.0)$ \\
\hline LV EF (\%) & & $>55$ & 83 & $60.0(50.0 ; 65.0)$ \\
\hline RVIDd (mm) & & $<33$ & 81 & $34.0(26.0 ; 47.0)$ \\
\hline TAPSE (mm) & & $<20$ & 60 & $19.0(14.5 ; 31.0)$ \\
\hline RAD (mm) & & $<44$ & 42 & $44.0(29.0 ; 53.0)$ \\
\hline $\operatorname{RAA}\left(\mathrm{cm}^{2}\right)$ & & $<18$ & 34 & $18.1(9.6 ; 37.0)$ \\
\hline TR (degree) & & $<2$ & 76 & $2.0(1.0 ; 3.5)$ \\
\hline PG TR (mmHg) & & $<35$ & 66 & $32.5(10.0 ; 56.0)$ \\
\hline PASP (mmHg) & & $<40$ & 66 & $40.0(15.0 ; 64.0)$ \\
\hline \multicolumn{5}{|l|}{ Treatment - initial } \\
\hline Systemic thrombolysis & & & & $13(15.7 \%)$ \\
\hline Anticoagulation only & & & & $69(83.1 \%)$ \\
\hline
\end{tabular}

Continuous parameters are described by the known $\mathrm{n}$, median $\left(5^{\text {th }}\right.$ and $95^{\text {th }}$ percentiles). Categorical parameters are described using absolute (relative) frequency; relative frequencies are only calculated from known data.

$\mathrm{n}$ - number of valid records for the variable in question, BMI - body mass index; FH VTE - Family History of Venous Thromboembolism; DVT - Deep Vein Thrombosis; PE - Pulmonary Embolism; CRP - C Reactive Protein; Hb - hemoglobin; INR - international normalized ratio; APTT - Activated Partial Thromboplastin Time; LVIDd - Left Ventricle Internal Diastolic Diameter; EF LV - Left Ventricular Ejection Fraction; RVIDd - Right Ventricle Internal Diastolic Diameter; TAPSE - Tricuspid Annular Plane Systolic Excursion; RAD - Right Atrium Diameter; RAA -Right Atrium Area; PG - Peak Gradient; TR Tricuspid regurgitation; PG TR - Peak gradient of tricuspid regurgitation; PASP - Peak systolic arterial pressure

patients with hemoglobin over $140 \mathrm{~g} / \mathrm{L}$, the cut-off was set to be 65 years of age (ROC: 67 years; $\mathrm{AUC}=0.727,95 \%$ IS: $0.545-0.918)$.

Hence, the final risk score stratifies patients into three groups: 1) patients with low hemoglobin $(\leq 140 \mathrm{~g} / \mathrm{L})$ with the lowest risk of persisting perfusion defects regardless of the age ( $n=50$ in our study population), i.e., patients in whom reperfusion was achieved the soonest; 2 ) younger patients $(\leq 65$ years of age) with high hemoglobin $(>140$ $\mathrm{g} / \mathrm{L})$, in whom the period until reperfusion was intermediate ( $n=24$ in our study population) and 3 ) older patients (> 65 years of age) with higher hemoglobin levels (> 140 $\mathrm{g} / \mathrm{L}$ ) who showed the highest risk of persisting perfusion defects ( $n=9$ in our study population); in other words, the perfusion defects persisted the longest in these patients (Fig. 1). The characteristics of the risk groups including hazard ratios of reperfusion and $95 \%$ confidence intervals are reported in Table 3.

Within 24 months from the PE episode, reperfusion was achieved in 47 (94.0\%) patients in the low risk group, 19 patients $(79.2 \%)$ in the intermediate risk group and $6(66.7 \%)$ patients in the high risk group of our study population.

The results from our study group ( 83 patients) indicate that in patients with high hemoglobin levels (over $140 \mathrm{~g} / \mathrm{L}$ ) who are younger than 65 years inclusive, the risk of persistence of defects is reduced by $79 \%$ compared to patients with the same hemoglobin levels who are older than 65 years. In patients with hemoglobin below $140 \mathrm{~g} / \mathrm{L}$, the risk of persistence of perfusion defects is $89 \%$ lower compared to the high-risk group. 
Table 2. Cox proportional hazards model of reperfusion - one-dimensional models based on the parameters acquired during the initial examination.

\begin{tabular}{|c|c|c|c|c|}
\hline & $\mathrm{n}$ & HR & $95 \% \mathrm{CI}$ & $P$ \\
\hline \multicolumn{5}{|l|}{ Demography+History } \\
\hline Age (years) & 83 & 0.989 & $0.975-1.004$ & 0.165 \\
\hline Sex & 83 & 1.388 & $0.854-2.255$ & 0.186 \\
\hline BMI & 80 & 0.934 & $0.885-0.985$ & 0.013 \\
\hline TED & 83 & 0.819 & $0.465-1.441$ & 0.488 \\
\hline DVT & 83 & 1.087 & $0.518-2.281$ & 0.825 \\
\hline $\begin{array}{l}\text { PE Risk Stratification } \\
\text { (Low/Intermediate/High) }\end{array}$ & 83 & 0.420 & $0.942-0.939$ & 0.450 \\
\hline $\mathrm{PE}$ & 82 & 0.318 & $0.775-2.190$ & 0.318 \\
\hline \multicolumn{5}{|l|}{ Lab tests } \\
\hline CRP $(\mathrm{g} / \mathrm{L})$ & 80 & 1.000 & $0.995-1.005$ & 0.920 \\
\hline Troponin $(\mu \mathrm{g} / \mathrm{L})$ & 77 & 1.123 & $0.730-1.729$ & 0.598 \\
\hline $\mathrm{Hb}(\mathrm{g} / \mathrm{L})$ & 83 & 0.975 & $0.958-0.992$ & 0.004 \\
\hline Thrombocytes $\left(10^{9} / \mathrm{mL}\right)$ & 83 & 1.001 & $0.997-1.005$ & 0.542 \\
\hline D-dimers $(\mathrm{mg} / \mathrm{L})$ & 73 & 1.000 & $1.000-1.000$ & 0.286 \\
\hline INR & 73 & 2.268 & $0.092-56.12$ & 0.617 \\
\hline APTT (s) & 61 & 1.008 & $0.992-1.025$ & 0.343 \\
\hline \multicolumn{5}{|l|}{ ECHO - initial } \\
\hline LVIDd (mm) & 82 & 0.986 & $0.953-1.020$ & 0.412 \\
\hline EF LV (\%) & 83 & 0.992 & $0.953-1.032$ & 0.685 \\
\hline RVIDd (A4C) & 81 & 0.966 & $0.928-1.005$ & 0.088 \\
\hline TAPSE (mm) & 60 & 1.026 & $0.976-1.078$ & 0.314 \\
\hline $\operatorname{RAD}(\mathrm{mm})$ & 42 & 1.004 & $0.973-1.035$ & 0.819 \\
\hline RAA $\left(\mathrm{cm}^{2}\right)$ & 34 & 0.961 & $0.916-1.009$ & 0.113 \\
\hline TR (degree) & 75 & 0.954 & $0.684-1.330$ & 0.780 \\
\hline PG TR (mmHg) & 66 & 0.984 & $0.963-1.005$ & 0.135 \\
\hline PASP (mmHg) & 66 & 0.981 & $0.962-1.000$ & 0.053 \\
\hline \multicolumn{5}{|l|}{ Treatment - initial } \\
\hline Systemic thrombolysis & 83 & 0.720 & $0.377-1.376$ & 0.320 \\
\hline Anticoagulation only & 69 & 1.027 & $0.484-2.177$ & 0.946 \\
\hline
\end{tabular}

$\mathrm{n}$ - number of valid records for the variable in question; HR - hazard ratio, CI - confidence interval, BMI - body mass index; FH VTE - Family History of Venous Thromboembolism; DVT - Deep Vein Thrombosis; PE - Pulmonary Embolism; CRP - C Reactive Protein; Hb - hemoglobin; INR - international normalized ratio; APTT - Activated Partial Thromboplastin Time; LVIDd - Left Ventricle Internal Diastolic Diameter; EF LV - Left Ventricular Ejection Fraction; RVIDd - Right Ventricle Internal Diastolic Diameter; TAPSE - Tricuspid Annular Plane Systolic Excursion; RAD - Right Atrium Diameter; RAA -Right Atrium Area; PG - Peak Gradient; TR Tricuspid regurgitation; PG TR - Peak gradient of tricuspid regurgitation; PASP - Peak systolic arterial pressure

\section{DISCUSSION}

Prediction scores play a major role in current clinical medicine to allow determining the likelihood of disease occurrence based on known parameters (e.g. Geneva score for determining the probability of PE based on the clinical symptoms) (ref. ${ }^{23}$ ) to estimate the likelihood of mortality of a particular disease in a patient or to guide the method of treatment (GRACE score, CHA2DS2VASc) $\left(\right.$ ref. $^{24}$ ).

In our study, we created a simple clinical risk prediction score for persistence of perfusion defects derived from long-term observation of a cohort of patients after the first episode of acute PE. The prediction score includes two parameters - hemoglobin levels and age at the initial examination for pulmonary embolism. The contribution of the presented study does therefore not rest in reporting raw data about number of patients, the novelty of this research lies in the analysis of individual risk fac- tors and in creating a scoring system for prediction of the persistence of perfusion defects after PE.

So far, only one study attempted to create a long time prediction risk score after PE for CTEPH development. Klok et al. ${ }^{25}$ established rule in and rule out risk scores in their retrospective analysis of a group of 772 patients with an acute PE episode and CTEPH incidence of $2.8 \%$. Based on a multivariate analysis, 4 independent predictive factors of increased risk were revealed: unprovoked pulmonary embolism, history of hypothyroidism, onset of symptoms more than 14 days prior to the diagnosis, and dysfunction of the right ventricle detected by either CTA or echocardiography. Those four factors were supplemented by two risk reducing factors - known diabetes and thrombolysis/embolectomy. Using logistic regression analysis, these factors were assigned individual score points (+6 to -3$)$. The score was developed to yield a binary result, with patients scoring below 6 considered to be low 
Table 3. Resulting Cox proportional-hazards model of reperfusion defects.

\begin{tabular}{lllll}
\hline $\begin{array}{l}\text { Risk of persisting } \\
\text { perfusion defects }\end{array}$ & $\begin{array}{l}\text { Group } \\
\text { characteristics }\end{array}$ & $\begin{array}{l}\text { Number } \\
\text { of patients }\end{array}$ & $\begin{array}{l}\text { HR (95\% CI) } \\
\text { of reperfusion }\end{array}$ & Interpretation \\
\hline High risk & $\mathrm{Hb}>140 \mathrm{~g} / \mathrm{L}$ and age $>65$ & $9(10.8 \%)$ & - & $\begin{array}{l}\text { Reference group with the highest } \\
\text { risk of persistence of the defects } \\
\text { The risk of persistence is decreased } \\
\text { by } 79 \%\end{array}$ \\
Intermediate risk & $\mathrm{Hb}>140 \mathrm{~g} / \mathrm{L}$ and age $\leq 65$ & $24(28.9 \%)$ & $0.21(0.07-0.97)$ & $\begin{array}{l}\text { The risk of persistence is decreased } \\
\text { by } 89 \%\end{array}$ \\
\hline Low risk & $\mathrm{Hb} \leq 140 \mathrm{~g} / \mathrm{L}$ & $50(60.2 \%)$ & $0.11(0.04-0.43)$ & \\
\hline
\end{tabular}

Three risk groups are defined according to the level of hemoglobin and the age at initial examination. The hazard ratio (HR) of the defect reperfusion is accompanied with a $95 \%$ confidence interval. Individual HRs are relative to the reference category, i.e., that with the highest risk of defect persistence (i.e. the lowest risk of reperfusion) (C-index $=0.624,95 \%$ IS: 0.549-0.692).

$\mathrm{HR}$ - hazard ratio, $\mathrm{CI}$ - confidence interval, $\mathrm{Hb}$ - Hemoglobin

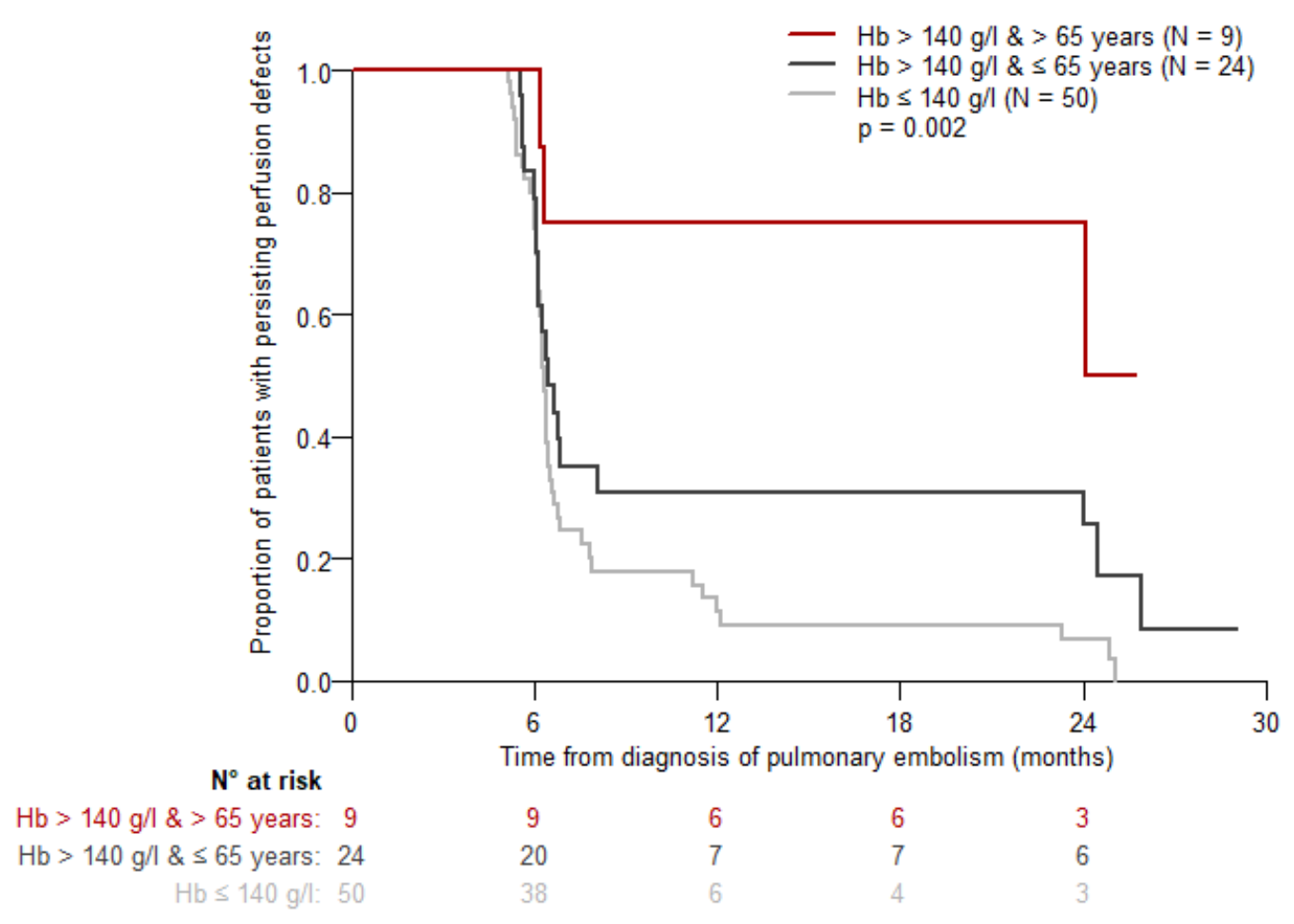

Fig. 1. Kaplan-Meier curves of persisting perfusion defects in the individual risk groups.

Reperfusion was considered as an event. The values of the curves correspond with the probabilities of persistence of the perfusion defects after reaching a given time point for individual risk groups. Absolute numbers of patients with persisting perfusion defects at individual time points and risk groups are indicated below the graph.

risk (incidence of CTEPH $0.38 \% ; 73 \%$ of patients) and remaining patients with total score over 6 considered to be in the high-risk group (CTEPH incidence of 10\%). While no follow-up was recommended for the low risk group, regular echocardiography follow-ups were recommended for the high risk group.

In our study aimed at prediction of the risk of persistence of perfusion defects (not of symptomatic CTEPH as in the work by Klok et al. ${ }^{25}$, age and hemoglobin levels were shown to be significant predictors, which is not in agreement with the study mentioned previously. Of the risk factors reported by Klok et al. for developing CTEPH, unprovoked PE was not significantly associated with in- creased risk of perfusion defects persistence in our group of patients. Similarly, thrombolysis was not found to act as a risk reducing factor in our study. Thyreopathy was not represented sufficiently in our patient group to allow us to draw any conclusions, and we have recorded neither the duration from the onset of symptoms to diagnosis nor the presence of diabetes. From the inverse point of view, Klok et al. did not record hemoglobin levels in their study; age was confirmed to be a risk factor of CTEPH but the odds ratio was low and, therefore, it has not been used for the calculation of their risk scoring system. Compared with their study ${ }^{25}$, however, our scoring system utilizes the potential of data assembled over time and we must of 
course take into consideration that our data focus on a condition preceding CTEPH, not CTEPH itself.

Higher hemoglobin levels and higher age were identified as predictors of persisting perfusion defects after PE in our study. Patients with higher age and increased hemoglobin were at the highest risk of persistence of perfusion defects; in other words, the time to reperfusion in this group was longer than in remaining risk groups. The identification of increased hemoglobin levels as a significant risk factor for prediction of perfusion defects is a novel finding. To the best of our knowledge, hemoglobin has not been investigated as a possible risk factor in any study focused on reperfusion disorders after acute PE published so far. However, myeloproliferative diseases including polycythemia are a well known risk factor of arterial and vein thrombosis as well as of CTEPH development ${ }^{26,27}$. The reason for thrombophilia in polycythemia patients is a greater blood viscosity leading to greater arterial wall shear stress combined with formation of aggregates of red blood cells in arterioles and capillaries. In turn, this leads to activation of platelets, prothrombogenic and proinflammatory state and, therefore, to disorders in the resolution of thrombi ${ }^{26}$. Neither of these factors are however specific for primary polycythemia and we feel that these factors can be associated with any increase in hemoglobin levels, thus possibly explaining our findings.

Our study has some limitations. One of them is the fact that the data used for calculation of the prediction scoring system originate from a relatively small group of patients, especially where patients with high risk of persisting perfusion defects are concerned. On the other hand, despite the fact that our study group is by an order of magnitude smaller than that of Klok et al. ${ }^{25}$, our study was prospectively monitoring patients for 24 months after a PE episode at several time points using echocardiography, scintigraphy and clinical examinations, which makes the data more valuable and reliable. Our aim was to construct a scoring system that would be able to reliably stratify the patients according to the risk groups rather than to predict reperfusion in a particular time point.

The estimated hazard ratios were internally validated using the bootstrap method. It would be however optimal to verify the functionality of the scoring system on an external group of patients. It is necessary to point out here, however, that not even the scoring system by Klok et al. has been validated so far. Quite the contrary - the work by Otero et al..$^{28}$ put a shade of doubt on the functionality of that scoring system. Otero et al. applied the score to a cohort of patients from the RIETE registry of PE in whom follow-up echocardiography examinations were performed (2256 patients). Out of 586 patients suspected of having CTEPH based on echocardiography examination, only 160 had the Klok's score over 6, i.e., belonged in the high risk group. On the other hand, it is also necessary to mention that the incidence of suspected CTEPH among patients in the RIETE registry was unusually high (26\%), which might have been caused by preselection of patients. Using the score in an unselected population with a typical (much lower) incidence of CTEPH would be much preferable for acquisition of reliable results.

\section{CONCLUSION}

In this study, we derived a simple and easy to use prediction scoring system which can identify patients with increased risk of reperfusion disorders after an acute PE episode. Despite the above mentioned limitation, we believe that such a simple score capable of categorizing patients according to the risk of persisting reperfusion disorders can be useful in clinical practice. As persisting perfusion disorders may precede the development of a serious chronic complication of acute PE - CTEPH - using our simple risk scoring system can identify patients with high risk of persisting perfusion defects in whom a more intensive follow-up regime would be beneficial.

Acknowledgements: This study was supported by the research project Progres Q38/LF1. Many thanks to Dr. Jaroslav Janosek for his valuable comments. The Authors would also like to express thanks to Dr. Jana Petrova (Department of Cardiology, Municipal Hospital Ostrava), Dr. Jana Vaclavkova, Dr. Vladimir Janovsky, Dr. Pavel Bindas (Department of Medicine, Silesian Hospital Opava) and Dr. Lubos Kraus (Department of Medicine, Novy Jicin Hospital) for their cooperation in recruiting patients, their follow-up and data collection.

Author contributions: JM: study design, data collection and interpretation, manuscript writing, final manuscript revision; TN, MS: data analysis, figures, manuscript writing, final manuscript revision; IS, PJ: study design, data interpretation, manuscript writing, final manuscript revision; PJ, IS: contributed equally towards the study as senior researchers.

Conflict of interest statement: The authors state that there are no conflicts of interest regarding the publication of this article.

\section{REFERENCES}

1. Heit JA. The Epidemiology of Venous Thromboembolism in the Community. Arterioscler Thromb Vasc Biol 2008;28(3):370-2.

2. Laporte S, Mismetti P, Decousus H, Uresandi F, Otero R, Lobo JL, Monreal M. Clinical Predictors for Fatal Pulmonary Embolism in 15,520 Patients with Venous Thromboembolism: Findings from the Registro Informatizado De La Enfermedad Tromboembolica Venosa (Riete) Registry. Circulation 2008;117(13):1711-6.

3. Goldhaber SZ, Visani L, De Rosa M. Acute Pulmonary Embolism: Clinical Outcomes in the International Cooperative Pulmonary Embolism Registry (Icoper). Lancet 1999;353(9162):1386-9.

4. Becattini C, Agnelli G, Prandoni P, Silingardi M, Salvi R, Taliani MR, Poggio R, Imberti D, Ageno W, Pogliani E, Porro F, Casazza F. A Prospective Study on Cardiovascular Events after Acute Pulmonary Embolism. Eur Heart J 2005;26(1):77-83.

5. Klok FA, van der Hulle T, den Exter PL, Lankeit M, Huisman MV, Konstantinides S. The Post-Pe Syndrome: A New Concept for Chronic Complications of Pulmonary Embolism. Blood Rev 2014;28(6):221-6.

6. Becattini C, Agnelli G, Pesavento R, Silingardi M, Poggio R, Taliani MR, Ageno W. Incidence of Chronic Thromboembolic Pulmonary Hypertension after a First Episode of Pulmonary Embolism. Chest 2006;130(1):172-5.

7. Dentali F, Donadini M, Gianni M, Bertolini A, Squizzato A, Venco A, Ageno W. Incidence of Chronic Pulmonary Hypertension in Patients with Previous Pulmonary Embolism. Thromb Res 2009;124(3):256-8.

8. Pengo V, Lensing AW, Prins MH, Marchiori A, Davidson BL, Tiozzo F, Albanese P, Biasiolo A, Pegoraro C, Iliceto S, Prandoni P. Incidence of 
Chronic Thromboembolic Pulmonary Hypertension after Pulmonary Embolism. N Engl J Med 2004;350(22): 257-64.

9. Pepke-Zaba J, Delcroix M, Lang I, Mayer E, Jansa P, Ambroz D, Treacy C, D'Armini AM, Morsolini M, Snijder R, Bresser P, Torbicki A, Kristensen B, Lewczuk J, Simkova I, Barbera JA, de Perrot M, Hoeper MM, Gaine S, Speich R, Gomez-Sanchez MA, Kovacs G, Hamid AM, Jais X, Simonneau G. Chronic Thromboembolic Pulmonary Hypertension (Cteph): Results from an International Prospective Registry. Circulation 2011;124(18):1973-81.

10. Yang S, Yang Y, Zhai Z, Kuang T, Gong J, Zhang S, Zhu J, Liang L, Shen $\mathrm{YH}$, Wang C. Incidence and Risk Factors of Chronic Thromboembolic Pulmonary Hypertension in Patients after Acute Pulmonary Embolism. J Thorac Dis 2015 7(11):1927-38.

11. Simonneau G, Torbicki A, Dorfmuller P, Kim N. The Pathophysiology of Chronic Thromboembolic Pulmonary Hypertension. Eur Respir Rev 2017;26(143).

12. Held M, Kolb P, Grun M, Jany B, Hubner G, Grgic A, Holl R, Schaefers $\mathrm{HJ}$, Wilkens $\mathrm{H}$. Functional Characterization of Patients with Chronic Thromboembolic Disease. Respiration 2016;91(6):503-9.

13. Ende-Verhaar YM, Huisman MV, Klok FA. To Screen or Not to Screen for Chronic Thromboembolic Pulmonary Hypertension after Acute Pulmonary Embolism. Thromb Res 2017;151:1-7.

14. Lang IM, Madani M. Update on Chronic Thromboembolic Pulmonary Hypertension. Circulation 2014;130(6):508-18.

15. Klok FA, van Kralingen KW, van Dijk AP, Heyning FH, Vliegen HW, Huisman MV. Prospective Cardiopulmonary Screening Program to Detect Chronic Thromboembolic Pulmonary Hypertension in Patients after Acute Pulmonary Embolism. Haematologica 2010;95(6):970-5.

16. McGoon M, Gutterman D, Steen V, Barst R, McCrory DC, Fortin TA, Loyd JE. Screening, Early Detection, and Diagnosis of Pulmonary Arterial Hypertension: Accp Evidence-Based Clinical Practice Guidelines. Chest 2004;126(1 Suppl):14s-34s.

17. Schembri GP, Miller AE, Smart R. Radiation Dosimetry and Safety Issues in the Investigation of Pulmonary Embolism. Semin Nucl Med 2010;40(6):442-54.

18. van Es J, Douma RA, Kamphuisen PW, Gerdes VE, Verhamme $P$ Wells PS, Bounameaux H, Lensing AW, Buller HR. Clot Resolution after 3 Weeks of Anticoagulant Treatment for Pulmonary Embolism:
Comparison of Computed Tomography and Perfusion Scintigraphy. J Thromb Haemost 2013;11(4):679-85.

19. Konstantinides SV, Torbicki A, Agnelli G, Danchin N, Fitzmaurice D, Galie N, Gibbs JS, Huisman MV, Humbert M, Kucher N, Lang I, Lankeit M, Lekakis J, Maack C, Mayer E, Meneveau N, Perrier A, Pruszczyk P, Rasmussen LH, Schindler TH, Svitil P, Vonk Noordegraaf A, Zamorano JL, Zompatori M. 2014 Esc Guidelines on the Diagnosis and Management of Acute Pulmonary Embolism. Eur Heart J 2014;35(43):3033-3069,3069a-3069k.

20. R Core Team R: A Language and Environment for Statistical Computing. https://www.R-project.org/. (01 Feb),

21. Therneau T A Package for Survival Analysis in S. 2015; Version 2.38 https://CRAN.R-project.org/package=survival.

22. Canty A, Ripley B. Boot: Bootstrap R (S-Plus) Functions. 2017. R Package Version 1.3-20. 2017.

23. Wicki J, Perneger TV, Junod AF, Bounameaux H, Perrier A. Assessing Clinical Probability of Pulmonary Embolism in the Emergency Ward: A Simple Score. Arch Intern Med 2001;161(1):92-7.

24. Fox KA, Dabbous OH, Goldberg RJ, Pieper KS, Eagle KA, Van de Werf F, Avezum A, Goodman SG, Flather MD, Anderson FA, Jr., Granger CB. Prediction of Risk of Death and Myocardial Infarction in the Six Months after Presentation with Acute Coronary Syndrome: Prospective Multinational Observational Study (Grace). Bmj 2006;333(7578):1091.

25. Klok FA, Surie S, Kempf T, Eikenboom J, van Straalen JP, van Kralingen KW, van Dijk AP, Vliegen HW, Bresser P, Wollert KC, Huisman MV. A Simple Non-Invasive Diagnostic Algorithm for Ruling out Chronic Thromboembolic Pulmonary Hypertension in Patients after Acute Pulmonary Embolism. Thromb Res 2011;128(1):21-6.

26. Adir Y, Humbert M. Pulmonary Hypertension in Patients with Chronic Myeloproliferative Disorders. Eur Respir J 2010;35(6):1396-406.

27. Bonderman D, Jakowitsch J, Adlbrecht C, Schemper M, Kyrle PA Schonauer V, Exner M, Klepetko W, Kneussl MP, Maurer G, Lang I. Medical Conditions Increasing the Risk of Chronic Thromboembolic Pulmonary Hypertension. Thromb Haemost 2005;93(3):512-6.

28. Otero R, Bertoletti L, Muriel A, Siniscalchi C, Jimenez C, Luis Lobo J, Kigitovica D, Quintavalla R, Rocci A, Jara-Palomares L, Monreal $M$, Investigators R. Role of a Clinical Prediction Score in a Chronic Thromboembolic Pulmonary Hypertension Rule-out Strategy. Eur Respir J 2018;51:4. 